\title{
Brigitte Falkenburg* Edgar Wind on Experiment and Metaphysics
}

https://doi.org/10.1515/jtph-2020-0038

Published online April 26, 2021

\begin{abstract}
The paper presents a detailed interpretation of Edgar Wind's Experiment and Metaphysics (1934), a unique work on the philosophy of physics which broke with the Neo-Kantian tradition under the influence of American pragmatism. Taking up Cassirer's interpretation of physics, Wind develops a holistic theory of the experiment and a constructivist account of empirical facts. Based on the concept of embodiment which plays a key role in Wind's later writings on art history, he argues, however, that the outcomes of measurements are contingent. He then proposes an anti-Kantian conception of a metaphysics of nature. For him, nature is an unknown totality which manifests itself in discrepancies between theories and experiment, and hence the theory formation of physics can increasingly approximate the structure of nature. It is shown that this view is ambiguous between a transcendental, metaphysical realism in Kant's sense and an internal realism in Putnam's sense. Wind's central claim is that twentieth century physics offers new options for resolving Kant's cosmological antinomies. In particular, he connected quantum indeterminism with the possibility of human freedom, a connection that Cassirer sharply opposed.
\end{abstract}

Keywords: cosmological antinomy, experiment, metaphysics, Edgar wind, embodiment

\section{Introduction}

Edgar Wind's Experiment and Metaphysics (Wind 1934, 2001) is a neglected work in the philosophy of science. When it was published, Wind, like Cassirer and many other scholars, had already left Germany. In the preface, that was written in great bitterness shortly before emigration, Wind sharply differentiates "elucidatory

This article is based on Falkenburg (2001), which was translated, abridged, and substantially revised for the present volume. I would like to thank two anonymous referees for their helpful comments on a previous version of this paper that helped to improve it.

*Corresponding author: Brigitte Falkenburg, Department of Philosophy and Political Science, TU Dortmund, 44221 Dortmund, Germany, E-mail: brigitte.falkenburg@tu-dortmund.de 
analysis" from the "declamatory broodings" of German philosophy of the time and attacks the "most prominent representatives" of Neo-Kantian "idealism" (like Heinrich Rickert and Bruno Bauch) who did not oppose to the Ungeist which made the rise of the National Socialist regime possible (2001, 2).

Experiment and Metaphysics shared the fate of lacking reception with several Neo-Kantian writings on the philosophy of physics from the 1930s. Cassirer's book on quantum mechanics, written in Gothenburg (Cassirer 1936), has finally received increasing attention in the last two decades (Schmitz-Rigal 2002). Grete Hermann's work, which contains an early refutation of von Neumann's proof against hidden parameters of quantum mechanics (Hermann 1935), has only recently been reedited and received (see Crull and Bacciagaluppi 2016; Hermann 1996; Herrmann 2019). The philosophy of science in American emigration, represented primarily by Carnap and Reichenbach, had no access to these Neo-Kantian writings until the post-war period, and the further development of the philosophy of science bypassed them.

This was particularly true for Wind's habilitation thesis, completed in 1929, which however broke with Neo-Kantianism under the influence of American pragmatism. Cassirer, Panofsky, and the other members of the habilitation committee appreciated its originality and analytical rigour but were critical of the results (Buschendorf 2001, 223-229). Due to the economic crisis, the publication of the book was delayed, and when it finally appeared after Wind's emigration, it was silenced and forgotten. After his emigration, Wind turned back to the topics of art history. Experiment and metaphysics remained his only work in the philosophy of physics, and its singular position in Wind's œuvre certainly contributed to its being forgotten.

For Wind himself, this work marked the decisive turning point in his exploration of art and its history. In it, he developed a concept of symbolic representation, or embodiment, which aimed at establishing a bridge between the methods of natural science and history and played a key role in his later writings on art history (see below Section 4). But Experiment and Metaphysics also deserves attention independently of this methodological bridge function. The work outlines a theory of experiment that is much more precise than Cassirer's remarks on measurement and it takes the theories of relativity and quantum mechanics as an impulse to examine Kant's doctrine of antinomy. With this thrust, it runs counter to all approaches of philosophy of science or Kant research of the time. The book title links experiment and metaphysics, against the positivist tendency to demand that the empirical and metaphysics be strictly separated.

Wind claims that the theories and experimental results of twentieth century physics provide new answers to traditional cosmological questions, which demonstrate that Kant's doctrine of the antinomies needs to be revised. This thesis 
stands in sharp contrast to the views of the Marburg school of Neo-Kantianism. For Natorp non-Euclidean geometry is only a useful mathematical tool of physics that does not change the role of Euclidean geometry as an indispensable precondition of physical knowledge (1910, 312-318), quite in the sense of Kant. Cassirer was also convinced that general relativity did not deprive Euclidean geometry of its methodological supremacy, and he relativized it to make it compatible with special and general relativity (1921, 85 and 97). Both views stood against re-examining Kant's doctrine of antinomy in the light of modern physics.

In Kant research and philosophy of science, the relation between the theories of modern physics and Kant's doctrine of the antinomy also remained neglected for a long time. Empiricist philosophy of science turned away from Kant's epistemology in view of relativity and quantum theory, and when it finally turned back to Kant and the Neo-Kantian background of logical empiricism (Friedman 1992, 1999), it did so from a historical point of view. Kant scholars analysed the structure of Kant's doctrine of the antinomy. They criticized or defended Kant's proofs, but paid little attention to the question of how the cosmological antinomies and their resolution relate to the theories of physics. The approach and thematic range of Wind's work thus differs strongly from the predominant traditions in the philosophy of science and Kant research. Therefore, I will present this approach here in its philosophical pretensions, without going into the details of Wind's Kant interpretation. ${ }^{1}$ I will also make no effort to compare Wind's approach to more recent work on the relations between twentieth century physics and Kant's antinomy doctrine. Instead, I will attempt to situate it relative to important positions of twentieth century philosophy of science, which is perhaps the most interesting aspect of the work beyond Wind's œuvre.

\section{The Approach of the Book}

During his stay in the United States from 1924-1927, Wind became familiar with American pragmatism. Taking up above all the writing How to make our ideas clear (Peirce 1878), he asked for standards of clear philosophical argumentation. The preface of 1933 strongly opposes an intellectual climate in which philosophy, instead of complying with its critical obligations, capitulates betraying the Enlightenment ideas (Wind 2001, 1-2). Explicitly referring to Heidegger and Jaspers, he criticizes forms of philosophy in which the art of argumentation has fallen into decline. We may compare Wind's pleas for conceptual clarity with Carnap's

1 The way in which Wind reads Kant's doctrine of the antinomy seems to agree with Cohen's interpretation in Kants Theorie der Erfahrung (Cohen 1871, 527-550). 
merciless syntactic and semantic analysis of some of Heidegger's phrases exposing them as pseudo-propositions that feign meaning where none exists (Carnap 1931). In contrast to Carnap, Wind is not interested in establishing meaning criteria to distinguish between scientific propositions and metaphysics. But his criticism also aims at philosophical terms lacking clarity. He is above all concerned with the cosmological foundation of the idealistic conception of freedom. The request to clarify it and to find out whether it has been shaken by modern physics leads him to examine Kant's cosmological antinomy.

By the "idealistic concept of freedom" Wind means the Kantian concept, which according to him had been criticized of being "too vacuous and shallow in its impotent universality" $(2001,2)$. He calls for getting to its roots in theoretical philosophy and for removing its grounds by a naturalistic criticism of the cosmological concept of freedom, which is based on the refutation of Kant's third cosmological antinomy. According to Kant, causality of freedom and causality of nature are in conflict, a conflict which he resolved in terms of his dualism of phenomena and noumena. To criticize the antinomy and Kant's resolution, Wind attacks Kant's tacit assumptions about the structure of nature on a large and on a small scale, which turned out to be inadequate in view of twentieth century physics. Wind is particularly interested in the claim that all processes in nature are completely determined, an assumption that is challenged by the probabilistic interpretation of quantum theory.

Around 1930, Wind was not the only one who connected the possibility of human freedom with the limitations of determinism resulting from quantum theory. Jaspers $(1932,190)$ also discussed this connection but warned against exaggerating the analogy between the missing determination of human actions and the missing determination of subatomic processes. In view of Wind's claim of analytical rigour, one will therefore ask for his arguments in favour of connecting the idea of human freedom and the contingency of microscopic events in quantum processes. In contrast to Wind, Cassirer was very critical of such a connection. In Determinism and Indeterminism, he gives detailed arguments why the indeterminism of quantum processes should not directly be linked to metaphysical speculations on the problem of freedom of will (1936, 197-213).

Wind's first reason for reconsidering Kant's doctrine of the antinomy in the light of non-classical, however, was general relativity:

Plunged by the conflict between Einstein's cosmology and transcendental dialectic, I asked how it is possible for a physicist to adduce experimental criteria for the solution of a problem which Kant, and even the fierciest opponents of Kantianism, had held to be insoluble on an empirical basis. $(2001,4)$ 
In his view, twentieth century physics, starting with Einstein's general relativity, refutes Kant's doctrine of the cosmological antinomies in general. For Wind, Einstein's theory clearly shows that physics provides definitive answers to questions about the nature of the universe, which according to Kant do not refer to an object of empirical knowledge and lead to an unresolvable conflict of reason with itself.

Three remarks should be made here. First, one should distinguish physical cosmology from the metaphysical cosmology which Kant attacks. The former is a theory about the physical universe. The latter is part of a rational system of metaphysics in Christian Wolff's sense, i.e., metaphysical cognition a priori. Second, Wind conflates both conceptions, following Kant. According to Kant, the metaphysical debates of his day demonstrate that metaphysical claims about the spatio-temporal world inevitably give rise to such a conflation. ${ }^{2}$ Kant's resolution of the antinomy then rests on criticizing this conflation and restricting the metaphysical principles of cosmology to their regulative use. Third, in the proofs of the first and second antinomy, Kant employed traditional metaphysical arguments concerning the size of the world and its ultimate substances (stemming, e.g., from the Leibniz-Clarke-debate), but he assumed that the spatio-temporal world was subject to a Newtonian physical cosmology. The theories of twentieth century physics revised this cosmology, and so Wind could be convinced that they make Kant's proofs of the antinomy pointless; and with them, the whole doctrine of the antinomy and its resolution.

It is remarkable that Wind looked for the conflict between Kant's transcendental philosophy and physics at a completely different point than the NeoKantians and other philosophers of science of the time did. In his book on Einstein's relativity, Cassirer (1921) had primarily discussed the question of whether Kant's Transcendental Aesthetic is compatible with the non-Euclidean geometry of general relativity. By distinguishing between topological and metric concepts and applying them to the empirical contents of space and time, he attempted to recover Kant's theory of space and time as the pure forms of intuition a priori as far as possible, from an epistemological point of view. Reichenbach $(1920,1922)$ had developed a related position, according to which Kant's doctrine of synthetic judgements a priori needs to be relativized. But neither Cassirer, nor Carnap (1922), nor Reichenbach, asked how the claims of Kant's doctrine of antinomy relate to the theories of twentieth century physics and their experimental test. It is this problem that makes up the originality of Wind's habilitation thesis. The structure of the work results from his approach to it. Given that the empirical

2 Therefore, Kant's cosmological antinomy arises from the topics of the mathematical antinomy. See Grier (2001, 181), and Falkenburg (2020a, 137-142, 158, 163). 
methods of physics substantially differ from everyday experience, he first develops a theory of experiment. On this basis, he then attempts to clarify the relation between Kant's cosmological antinomy and classical as well as twentieth century physics.

Wind's theory of the experiment has holistic features (like Cassirer's), and precisely for this reason he can link it to the cosmological questions of traditional metaphysics (in contrast to Cassirer). Wind claims that

the instruments which serve to investigate the worlds are themselves integral parts of the world that is the subject of investigation, and are therefore affected in turn by the cognition which they themselves have transmitted. 'Metaphysics' (in the sense of the doctrine of the unknown whole) and 'empirical science' (the knowledge of those parts accessible to us) are inextricably linked in this cyclical pattern of thought. For every experiment contains and tests a hypothesis concerning the whole, yet every decision concerning the whole leads [...] to experimental conclusions. The thesis of the book is that, in spite of transcendental dialectics, the questions posed in the 'cosmological antinomies' relate in this sense to 'real' decisions. (Ibid., 5)

For Wind (unlike Carnap), 'metaphysics' is not simply an antonym to 'empirical cognition' in the sense that metaphysical terms lack of an empirical interpretation and empirical propositions are free of metaphysics. For him, metaphysics is the "doctrine of the unknown whole" and empirical cognition is the "knowledge of those parts accessible to us", and both are entangled in a "cyclical pattern of thought" established by the theory according to which the measuring devices of an experiment are designed. This conception of metaphysics crucially differs from Kant's (see below Section 5). Based on it, Wind opposes Kant's critical claim that the cosmological problems of metaphysics are undecidable, or, to put it in terms of Kant's logic (Kant 1800, § 30), that the claims of traditional (metaphysical) cosmology about the world as a totality are only problematic judgments, whereas the judgments of an empirical science are assertoric. According to Wind, Kant's distinction between empirical (assertoric) and metaphysical (problematic) cognition of the world is not viable.

Wind makes the following holistic claim. The empirical science of physics is based on theory-laden experimental results rather than mere sensory data. Hence, knowledge of the "empirical" parts of the world is only possible due to theoretical assumptions about the "metaphysical" totality of the world. The "empirical" parts of the world are accessible through single experimental phenomena and measurement results, whereas the "metaphysical" whole consists of the totality of all law-like relations, which are effective in the respective area of phenomena as well as in the measuring instruments and experimental devices of physics, and which can never be completely known. The measurement theory underlying an experiment covers 
certain partial aspects of these relations. For Wind, in every experiment of physics the access to single empirical phenomena is interwoven with metaphysical assumptions about the laws that govern them.

Wind considers the questions of cosmology to be principally decidable. His point is that certain cosmological assumptions, e.g., about the structure of space and time, enter our measuring theories. As far as the experimental method of physics is at all capable of providing knowledge of nature, these assumptions must then be to some extent empirically testable. He emphasizes this conviction referring to Peirce's maxim from How to make our ideas clear (1878), according to which any question that has a clear meaning can be answered by carrying the investigation far enough (Wind 2001, 6). ${ }^{3}$ In addition, he claims that the cosmological problems which Kant considered undecidable can be empirically decided in a finite number of steps of investigation. For all of Kant's antinomies, he relies on the finiteness of the object of investigation (see below Section 7). This plea for the finiteness of the objects of cosmological cognition does not only remind of Hilbert's finitism (Hilbert 1925) which was very influential at that time. It also fits without rupture into the philosophy which he fought against, not least Heidegger's and Jaspers's.

\section{The Theory of the Experiment}

A physical theory and an experiment to probe it cannot be independent of each other. In general, the measuring instruments are subject to the theory to be tested, because in order to perform the experiment, the measuring laws are to be applied to the phenomena in the domain of the theory. In view of this fact, Wind begins his investigation by stating a kind of hermeneutic circle of physical research, which for him demonstrates an important methodological parallel between physics and history:

Just as the physical instrument is a physical object and therefore subject to the laws which it intends to test, the historical document is itself an object of historical inquiry; for it participates in the historical life which it helps to investigate. This fact has always been recognized by hermeneutical theory. (Wind 2001, 19)

3 Cf. Peirce $(1878,269)$ : „To this I reply that, though in no possible state of knowledge can any number be great enough to express the relation between the amount of what rests unknown to the amount of the known, yet it is unphilosophical to suppose that, with regard to any given question (which has any clear meaning), investigation would not bring forth a solution of it, if it were carried far enough.“ 
The measurement methods used to carry out an experiment must be subject to the very theory tested by the experiment. Vice versa, the accuracy of the measurement results depends on the adequacy of the measurement theory. $\S 1$ of Experiment and Metaphysics gives two examples for this mutual dependence of theory and measurement: The measuring laws of mechanics are based on assumptions about the metric properties of rigid bodies, which themselves fall in the scope of mechanics. Likewise, any temperature measurement is based on the thermodynamic assumption that certain materials expand uniformly in a certain temperature range, when heated. ${ }^{4}$ This holistic relationship between a theory and its measuring methods has been known for a long time, even though its formal structure was investigated only much later (Sneed 1971). Wind (2001, 7-9) only refers to Comte and to Eddington. But Mach (1883) and Hertz (1894) already noticed the possibility of eliminating the concept of force from mechanics (which is a consequence of “T-theoreticity" in Sneed's sense). Poincaré (1902, 1908) and Duhem (1906) emphasized the theory dependence of the measurement methods of physics. Cassirer discussed it in his Substance and Function (1910, 141-147). Einstein, who based his special theory of relativity on an operational concept of simultaneity, brought it up against a one-sided operational view of physical concepts. In view of Heisenberg's operational matrix mechanics, he emphasized that only theory decides what can be measured (Heisenberg 1969, 63).

In the Marburg school, Cohen (1914) and Natorp (1910) had similar insights. Cohen once points to a text passage from Hertz's mechanics $(1894,9)$ according to which the empirical elements of physics are hidden and merged with theoretical elements in the fundamental laws of physics. Cohen comments it with the following words:

If such a mixture of the logical elements with those of experience is possible, this demonstrates a connection of thought-elements whose intimacy is not captured adequately by the expression 'concealed'. (Cohen 1914, 126).

Here, Cohen subsumes the "logical elements" together with "those of experience" under the "thought-elements"; shortly after, he then speaks of "thinking the concepts into the things to be constructed by means of them" (Cohen 1914, 127). ${ }^{5} \mathrm{He}$ thus tends to interpret the theory dependence of experimental experience in such a way that even the measured values of theoretical terms like force are constructs of

4 Kuhn (1961) showed that the theory dependence of the measuring methods made the development of measuring theories and devices particularly difficult for such concepts as force or temperature, thus delaying the quantitative validation of physical theories.

5 For the translation of this passage, see the remarks in Falkenburg (2020b, 14). 
our thinking (Falkenburg 2020b, 14). This constructivist interpretation of physical magnitudes was also shared by Natorp (1910).

In Wind this constructivist tendency can be found again, but he relativizes it by stating that the question of whether the theoretical prediction and the measured value agree or not is in general contingent. Like the physicists of that time, in particular Einstein, Wind ultimately advocates a realistic view of the theoretical terms and laws of physics, although it remains to be qualified which variant of realism he supports, and how it relates to the constructivist elements in his thought. For him, physics and the use of physical instruments aim at obtaining knowledge of the world, and he considers it possible to discover genuine laws of nature by means of experiments.

From the point of view of scientific realism, the circle of measurement is a major epistemological problem, which the proponents of instrumentalism or constructivism avoid: How can one ever test by experiment the truth claim associated with a theory, if no theory-independent measuring method is available? As we know today, this vicious circle is due to the underdetermination of scientific theories by evidence (Stanford 2017). The physicists find their ways to escape from it by carefully distinguishing between the well-confirmed background theories employed in their experiments and the theories under test (see, e.g., Galison 1987; Falkenburg 2007).

For Wind, the "reason" for the use of measuring instruments is to discover the "cosmic laws" to which the measuring instruments are subject (Wind 2001, 10). If the way in which the measuring instruments work is completely known, the laws that they employ should give rise to measuring the true values of physical magnitudes (apart from measurement errors). The view that physics aims at cognition of the world is bound to a correspondence theory of truth. It presupposes that the laws of mathematical physics and the measured magnitudes are true if and only if they correspond to what is indeed the case in the experiment. However, the circle of measurement unfortunately implies that this correspondence cannot be empirically tested, i.e., no independent correspondence criteria can be given for establishing a law and determining exact measurement outcomes. This seemingly vicious circle poses two complementary problems (Wind 2001, 7-10):

1. How can one be sure of obtaining precise or accurate measurement results without knowing whether the laws involved in the measurement are universal?

2. How can one prove the unrestricted applicability or universality of laws without knowing whether the measurement results obtained with them are accurate?

Wind makes two assumptions. (i) True laws are universal, i.e., they have unrestricted validity; (ii) the performance of experiments and the experimental validation of theories require universally valid laws. Then, a true law and the 
measurement method by which it is tested relate like a universal proposition and a singular instance of it.

From today's point of view, this simplifying view of the relation between physical laws and measuring methods needs to be modified in various respects. It has long been considered a serious problem how to define the class of instances relative to which a law-like proposition may be considered universally valid (Goodman 1955). Furthermore, the question of whether the laws of physics are universal is disputed today by strong arguments. The measurement laws of physics are either phenomenological laws, which are not embedded in a comprehensive theory, or they are obtained from general theories by certain contingent application conditions, which are often not exactly known. For theory formation in physics, therefore, the circle of measurement is usually not as disastrous as it would be in the ideal case of a universal theory. It is typically disabled by requiring only the empirical adequacy of a measurement theory for a certain class of instances, instead of truth and universality. This condition is already met if a wellestablished measurement law can be considered as an approximate specific case of the theory to be tested. In experimental physics, this assumption is usually for good reasons taken to be true.

Thus, Wind's theory of experiment is based on stronger assumptions about the universal validity of the measurement laws than the experiments of physics themselves. If Wind had discussed the relation between theory and measurement method for the case of quantum theory, on which his criticism of Kant's account of freedom in Part 2 of the book is based, he would not have found a circle of measurement. A qualified version of Bohr's dictum that quantum phenomena must be expressed in classical terms holds up to the present day, given that many of them are measured with (at least semi-) classical methods. ${ }^{6}$ Wind, however, chooses that case of relation between theory and measurement which is at the same time the simplest and most unfavourable, namely that of geometry. As the general theory of relativity teaches, the choice of a geometry is closely related to theoretical assumptions about the metric properties of the bodies used for length measurement. The choice of geometry is fundamental for physics in total. It is part of every physical law and every experiment. If a unified description of nature is aimed at all, it is unavoidable to claim the universal validity of geometry. The way out of the circle of measurement that Wind saw see under these strong preconditions was not Poincaré's conventionalist solution (which he sharply criticized in $\S 4$ ), but the notion of embodiment, which he introduces as follows.

6 Quantum physics depends on classical measurement laws which are on a probabilistic level approximately valid. For details, see e.g., Falkenburg (2007). 
If a measurement method falls within the scope of a theory to be tested and no other method is available, only coherence criteria for the truth of the theory remain. According to Wind (2001, 10-11), the following three aspects of a measurement method must be coherent with each other:

1. The system of axioms and theorems that establishes a measurement theory and defines the physical magnitudes that are measured (e.g., Euclidean geometry),

2. the choice of concrete objects which serve as standards or measuring instruments and are assumed to instantiate the laws of the axiom system (e.g., rigid rods), and

3. the empirical act of measurement, which consists in applying the standards or measuring instruments to the objects to be examined and results in a measurement outcome.

Wind considers the axiomatic foundations (1) and the measurement laws based on them as verités de raison in Leibniz's sense. The theoretical truths of the axiom system are only subject to logical consistency criteria. He contrasts them with the verite de fait of the coincidence or non-coincidence of an empirical object with the points of a scale calibrated by means of a standard, which is "a physical event, the outcome of which is purely a matter of empirical observation” (2001, 11). An empirical truth (3) which results from the act of measurement is contingent, and it can be stated by an observation sentence in the strictly empiricist sense. The measurement laws and the empirical observation sentences do not correspond directly to each other; they are only linked with each other by means of the standards or measuring instruments (2). Wind emphasizes that the choice of the standards or measuring instruments can neither be logically justified nor be determined by empirical observation, and he considers this choice as an act of embodiment or symbolic representation (ibid.).

In terms of the measurement theory developed by empiricist philosophy of science, the standard or measuring instrument is an (approximate) empirical model of the axiom system (Krantz et al. 1971; Suppes 1962). Wind's analysis of the elements of measurement could easily be formalized in the context of the axiomatic theory of measurement. It is much closer to the model-theoretical (or 'semantic') view of theories (Sneed 1971; van Fraassen 1980, 1987) than to Carnap's 'syntactic' view (Carnap 1956, 1966). According to Carnap, the theoretical terms of physics can be interpreted via observation terms and correspondence rules. According to Wind, in contrast, it is not possible to interpret the theoretical axioms and laws (1) of measurement completely and accurately by the outcomes of the measurement acts (3) or by the observation sentences stating them. The data obtained from comparing objects with standards, or from the pointer positions of 
measuring instruments, represent the measurement laws at most partially and without precision.

\section{The Notion of Embodiment}

The notion of embodiment or symbolic representation is the key concept of Wind's theory of experiment. It is of immense importance for his later writings, given that it is for him a concept in which the methods of natural science and history meet, and which establishes the link to his work in art history (Buschendorf 1985; Wind 1936). Based on this notion developed under the influence of pragmatism (Krois 1998, 5-15), ${ }^{7}$ Wind transforms Cassirer's approach to symbolic forms into his own, genuine account of symbolic representation. The main point of difference between Wind and Cassirer is that for Wind a symbol has a real, observable content via embodiment, whereas for Cassirer it has not (ibid., 13). This view distinguishes him also from Duhem and may be the reason for his neglect of Duhem's philosophy of physics (see below).

The embodiment of an axiom system in an appropriate measuring instrument is achieved by an act which Wind considers as arbitrary and purposive $(2001,11)$. It is arbitrary because it is based on the free choice of the experimenter, and purposive because the experimenter selects (or constructs) a measuring instrument to give it a certain function. For Wind, an empiricist approach, however elaborate, can never capture the nature of measurement. An additional analysis in teleological terms is required, as provided by the theory of action. In this regard, his conception of embodiment comes close to a constructivist approach to the experiment based on an interventionist theory of causation according to which measurement outcomes are nothing but the results of human actions. ${ }^{8}$ However, Wind did not endorse such an anthropocentric account of measurement. For him,

7 Krois explains in detail the influences under which Wind developed his conception of embodiment during his stay in the USA, in the years 1924-1927. There is no English translation of his important article, therefore I give some of its details here. In 1924 Wind gave a talk at the American Philosophical Association, which was introduced by Morris R. Cohen, the editor of a first collection of Peirce's writings (Peirce et al. 1923). Wind then began to read Peirce and took up particularly the essay How to make our ideas clear. Other important influences on Wind were the contact with Sidney Hook, author of the book The Metaphysics of Pragmatism (1927), John Dewey's book Experience and Nature (1925), Charles I. Lewis's conceptual pragmatism, and Whitehead's process philosophy (concerning the latter influence, Krois gives no detail).

8 Such a version of constructivism was much later defended by Tetens (1987). It differs from Cohen's or Natorp's constructivism mentioned above in that it focuses on experiment as a kind of human action rather than the theory dependence of scientific experience. Both versions of constructivism have in common that they are incompatible with scientific realism. 
the purpose of the measuring instrument is not limited to the teleological structure of human actions. Rather, it is to select it in such a way that it leads to a metric scheme that expresses the contingent outcomes of measurements, in terms of equations that correspond to the axioms of the measurement theory.

In his view, the choice of the measuring instrument is purposive in two respects. On the one hand, the instrument should be such that it is a means to an end of a goal-oriented human action; this is its teleological aspect. But on the other hand, it should be such that its way of functioning corresponds to the given theory of measurement. The second respect expresses an adequacy condition, i.e., a correspondence criterion which is crucial for the applicability of a measurement method and which the measuring instrument must meet to give useful measurement outcomes. Thus, the circle of measurement on the one hand implies that the measuring instruments must be selected according to coherence criteria, while on the other the measuring instruments only serve their purpose if they are adequately selected, i.e., satisfy an adequacy condition.

According to Wind, the adequacy condition can only be approximately met. The theoretical measurement axioms never do completely justice to the way in which a concrete measuring device works. Therefore, it is only approximately possible to realize the measurement laws by physical objects which serve as measuring instruments. Similarly, the transformation of an artistic conception into reality is an act of embodiment which demonstrates its aesthetic validity by being exposed to the danger of failure $(2001,40)$.

For Wind, the symbolic representation of the measurement laws by a measuring instrument embodies a true theory, which our theory formation only captures fragmentarily and imperfectly. Whether the measuring devices are adequate or not becomes indirectly evident in the success or failure of the experiment. It is not up to the experimenter whether the use of the measuring devices succeeds or fails, but due to unknown physical causes (ibid, 19). The success or failure of an experiment is for Wind "nothing less than a metaphysical manifestation", in which an unknown metaphysical instance (which we may call 'nature', 'universe', or 'world') counters our actions, such that any measurement or experiment is "provoking an entirely meta-logical act" (ibid, 22).

Wind's concept of embodiment marks the point at which the circle of measurement can be broken. The reliability of the measurement outcomes depends on the accuracy with which the measuring instruments realize the measurement laws. If the axiom system, its realization by the instruments, and the empirical relations between measured objects and the metric scheme are incompatible, the measurement is grounded in an inadequate theory. In accordance with the underlying coherence criteria, the measurement laws and measuring instruments prove their reliability by showing no discrepancies between the measurement theory and the 
outcomes. The (approximate) agreement between a theory and the measurement results obtained with it is the criterion for judging whether a physical theory is a good candidate for being true.

As Wind correctly sees, the processes of theory formation in physics usually escape the circle of measurement by iterative procedures that bring physical laws and measurement methods into convergence, or in his terms, by a "cyclical progression" (ibid., 33). As he puts it, "the logical circle [...] turns out to be a methodological cycle" which is "self-regulating" (ibid., 34). The physicists start from a measurement theory, select measuring instruments that embody the measurement laws, and perform measurements. If too many discrepancies occur between the underlying theory and the measurement outcomes, they will try to modify the theory. Finally, they will obtain more precise measurement outcomes that are compatible with the modified theory.

According to Wind, the genuine discoveries of physics present themselves as discrepancies (ibid., 20), or, as Kuhn (1961, 1962) later put it: as quantitative anomalies. In accordance with Kuhn's later insights and the Duhem-Quine thesis, but in contrast to Popper's falsificationism, Wind believes that discrepancies alone do not yet suffice to reject a theory. Wind's holistic theory of the experiment is indeed very similar to that of Duhem, as the following passage demonstrates:

If an experiment fails to confirm an individual hypothesis, this failure reflects not only upon the hypothesis as such, but the entire system of assumptions on which it was founded. [...] In this sense it is no exaggeration to say that with every individual experiment a whole system of experimentation comes to a test. (Wind 2001, 33-34)

It is therefore particularly striking that Experiment and Metaphysics nowhere mentions Duhem's Aim and Structure of Physical Theories (1906). ${ }^{9}$ Wind's notion of the "symbolic representation" of theoretical relations by measuring devices is also reminiscent of Duhem, even though his account of symbols is contrary to Duhem's. For Duhem, a symbol provides an abstract model of concrete things. It is a sign that represents existing objects in an abstract and idealized way.

9 The habilitation report from Hamburg (Buschendorf 2001, 223-229) also points to the fact that Wind did not refer to the origin of criticizing the empiricism, namely Duhem's criticism of Mach. Cassirer, however, did not hold the neglect of Duhem against Wind. His differences with Wind concern another topic, he disagrees with the way in which Wind connects quantum indeterminism with the conception of human freedom (Cassirer 1936, 197-213). In Determinism and Indeterminism Cassirer refers to Wind's theory of the experiment in the positive, without mentioning Duhem: 'Concerning the 'Circle of physical investigation', cf. the excellent presentation of Edgar Wind in Das Experiment und die Metaphysik, Tübingen 1934; with the systematic conclusions which Wind draws from this circle concerning the relationship between physics and metaphysics, however, I cannot agree” (1936, 137, n. 43). 
Dynamic quantities of physics such as mass, charge or magnetic field strength are for him symbols which comprise large numbers of different phenomena and represent them in abstract classes. Duhem interprets physical theories in terms of instrumentalism, he argues that the symbolic representation of the phenomena by physical concepts and laws cannot be taken for true. In contrast, Wind considers the measurement theory embodied in the measuring devices to be at least approximately true. A symbol in Wind's sense is a concrete, empirical model of an abstract fabric of ideas, it embodies a true theory which is increasingly approximated by the process of theory formation in physics. For Wind, a symbol is a part of physical reality that embodies abstract or ideal relationships by means of concrete objects. Accordingly, a measuring instrument of physics is for him a "metaphysical symbol” (ibid., 22) which perfectly realizes, or models, the laws of nature which we can never completely know.

\section{Metaphysics and the Empirical}

'Metaphysical' is for Wind a counter-term to 'empirical', but in quite another sense than it is for the logical empiricists. Metaphysics relates to empirical knowledge like the unknown whole, the universe, to its empirically accessible parts. This view of metaphysics reminds of what Kant called the transcendental cognition of the world and considered to belong to the transcendent part of the metaphysics of nature, in the Architectonic Chapter of the Critique of Pure Reason (Kant 1781/1787, A 846/B 874). According to both accounts, metaphysics exceeds the limits of possible experience. There is, however, a crucial difference between them. For Kant, the conception of the world as a totality is a purely rational notion a priori, which by the metaphysical claims of cosmology becomes conflated with the concept of the spatiotemporal world, giving rise to the cosmological antinomy. Wind's account, in contrast, suggests that such a conflation is possible and legitimate, and that the world as a metaphysical totality is not completely inaccessible.

According to Wind, the delimitation between metaphysics and empirical knowledge is shifting in the process of theory formation of physics. Neither the empirical facts confirmed by experiment nor the untested metaphysical hypotheses about the universe are fixed once and for all. He emphasizes that the empirical basis of a theory changes in scope and structure over time, given that it depends on the theory and the process of theory formation depends on time. Therefore, he criticizes the empiricist conception of facts; for him, the "cognition of facts" is "progressive" (2001, 31). But the measurement outcomes are contingent, i.e., not 
determined by theory, and so is their agreement or discrepancy with the theoretical predictions:

The physical fact is registered by an instrument, and instruments are the result of constructions. The fact as such, therefore, reflects all the systematic problems of construction and interpretation. [...] But, at the same time, we appeal to something more than that. We appeal to those occurrences which have tested the system. [...] For, although we know the meaning of these occurrences only in terms of the presupposed system, we cannot predict their occurrence. $(2001,21)$

On this basis, he keeps modified conceptions of the 'empirical' and the 'metaphysical'. For him, metaphysics and the empirical are intertwined. The empirical, as the collection of contingent measurement results, is always based on theoretical assumptions about the unknown whole of the universe. In this way, he reconciles a constructivist view of scientific facts with a position of scientific realism. For him, the theory formation processes of physics come increasingly close to truth, bringing theoretical predictions into increasingly better agreement with experimental results by refined measurement methods. It is not possible to enforce the agreement of theoretical predictions with experimental results arbitrarily by means of ad hoc hypotheses. The task of the theory formation process is rather to separate the "neutral" hypotheses of physics, which cannot be tested by experiments, from the "real" hypotheses, which may lead to discrepancies between theory and experiment. ${ }^{10}$ A stable discrepancy, or (in Kuhn's terms) a quantitative anomaly that cannot be eliminated without changing the theory, confronts us with the unknown whole of the lawful connections of the phenomena. In this sense, Wind considers the success or failure of an experiments as a "metaphysical manifestation" (metaphysisches Signal) that indicates whether the fabric of theoretical assumptions underlying an experiment provides an adequate description of a part of nature, or not. The instance that becomes manifest in this signal is metaphysical for three reasons, according to him (ibid., 38-41):

(1) We have no control of it. In Kantian terms, the experiment puts a question to nature, but the answer 'yes' or 'no' is "heteronomous to thought" (dem Gedanken heteronom). ${ }^{11}$ The signals of this metaphysical instance do not derive from our theories, they are contingent.

10 The distinction between real and neutral (or indifferent) hypotheses is due to Poincaré (1902, 180-181); cf. the editor's remark in (Wind 2001, 18, n. 16).

11 Edwards translates: "subject to different laws from the thought" (ibid., 38). - Wind here refers to the famous passage in the preface B to Kant's Critique: "Reason, in order to be taught by nature, must approach nature with its principles in one hand, according to which alone the agreement among appearances can count as laws, and, in the other hand, the experiments thought out in accordance with these principles - yet in order to be instructed by nature not like a pupil, who has 
(2) The metaphysical instance is "by its nature unknown to us" (ibid., 39). It is not accessible to our cognition, our account of it is non-epistemic. One may call it “transcendent”, but not in Kant's sense. In contrast to Kant's noumenon, it manifests itself and thereby we may obtain increasing knowledge of it. ${ }^{12}$

(3) Our knowledge of it depends on the occurrence of regularities. Nomological hypotheses rely on reproducible measurements and experimental results. It manifests itself as a law-like structure, the existence of regularities is (in Kantian terms) a condition of the possibility of our experience of it.

Wind's conception of the "metaphysical signals" given by the outcome of experiments may be read as follows. In experiments we encounter a contingent reality, against which our theories can fail. For Kant, nature's answer 'yes' or 'no' in an experiment depends on reason's principles and is therefore by analogy a case for transcendental idealism (Kant 1781/1787, B xiii-xiv). For Wind, in contrast, the contingency of measurement outcomes provides a naturalistic principle for refuting the constructivist views of the Marburg school as well as Kant's transcendental idealism.

To attack the grounds of transcendental idealism Wind finally turns this principle against Kant's cosmological antinomy. He challenges Kant's claim that the cosmological judgments about the world as a totality are not assertoric, but problematic (Wind 2001, 16). For Wind, a cosmological assumption which can be embodied by measuring instruments, is a "real" hypothesis, whereas the cosmological judgments about the world in total were "neutral", empirically undecidable hypotheses, for Kant as well as for Wind. Wind's claim that "real" cosmological hypotheses can be tested is stronger than falsificationism allows. Perhaps the famous confirmation of general relativity during the 1919 eclipse in mind, he is convinced that such a test is an experimentum crucis (ibid., 18); if the experiment succeeds, the hypothesis is proven to be approximately true. In view of the holistic relation between theory and experiment, this verificationist thesis is problematic (Duhem 1906; see also Rampley 2001, xx-xxi). However, this claim is Wind's starting point for criticizing Kant's cosmological antinomy.

recited to him whatever the teacher wants to say, but like an appointed judge who compels witnesses to answer the questions he puts to them." (Kant 1787, B xiii).

12 According to Wind (2001, 40, n. 40), it may be called 'transcendent'. In his view, however, this transcendent entity is "not only, as it is frequently conceived, the unknown in an absolute sense that concerning which nothing can be experienced - but also that 'unknown' which manifests itself and can therefore be defined as unknown only from the point of view of a historical stage of knowledge" (ibid.). 


\section{The Critique of Kant's Doctrine of Antinomy}

Wind attacks the grounds of Kant's transcendental idealism, the distinction between phenomena and noumena. According to Kant, this distinction is enforced by the cosmological antinomy. He considers the antinomy of pure reason a thought experiment that refutes transcendental idealism on pain of contradiction (Kant 1781/ 1787, B xviii-xxi; see Falkenburg 2018a, 2018b and 2020a, 216-223). Kant's experiment of pure reason is intended as a philosophical experimentum crucis, to put it in Wind's terms (2001, 56-58). For Kant, the concept of the world as a totality of appearances is self-contradictory, if understood as a thing-in-itself (Kant 1783, §52c). It is supposed to consist of appearances, and at the same time, to be the unconditioned totality of all conditions of appearances. It is defined as an object of experience, or phenomenon, and alike an entity beyond any possible experience, or noumenon. This inconsistent concept of the world is the middle term of the cosmological syllogism from which the antinomy arises (Kant 1781/1787, A 499/B 527), and which turns out to be "nonsensical" in the first and second antinomy, and "ambiguous" in the third and fourth (Wind 2001, 57). Kant's resolution is that in in the first and second antinomy, the conflicting propositions are false, whereas in the third and fourth, the conflict is only apparent and both antithetic propositions may be true, opening the possibility of a causality of freedom beyond the causality of nature.

It can be shown that the antinomic structure primarily arises from the first and second antinomy, the so-called 'mathematical' antinomy (Grier 2001, 18), namely from the way in which Kant's conception of the mathematical infinite applies to cosmology (Falkenburg 2020a, 137-142). The 'mathematical' antinomy deals with the spatio-temporal extension of the universe and the ultimate substances in the world. For these topics, the respective claims about the appearances and their noumenal totality, the spatio-temporal world, cannot be disentangled, and this is the reason why Kant considers the antinomy inevitable, in contrast to his precritical account of cosmology. Detailed analysis shows in addition that Kant's transcendental idealism, in particular the distinction between phenomena and noumena, is sufficient, but not necessary for a resolution of the antinomy (Willaschek 2018, 245-249).

Hence, with the first antinomy Wind indeed attacks the crucial point of Kant's argument in favour of transcendental idealism. ${ }^{13}$ Assuming that the cosmological

13 Therefore, I do not agree with the following claim: "Wind's assertion that the resolution of the first antinomy casts into doubt the entire epistemological basis of Kant's philosophy is rather less convincing [...] Even if the structure of space can now be determined for sure, from a Kantian perspective this still only concerns the structure of phenomenal space and the phenomenal universe, not the noumenal thing-in-itself which [...] may have no spatio-temporal character at all." 
concept of the world as a totality of appearances is not self-contradictory, he demonstrates how the experiments and theories of contemporary physics avoid Kant's mathematical antinomy. Modern cosmology and particle physics are no longer bound to the traditional alternatives concerning the structure of the world on a large and small scale, which Kant attacked. There is no evidence that the theories of twentieth century physics become entangled in Kantian antinomies.

It has been emphasized above that Kant considered it inevitable to conflate physical cosmology with metaphysical claims about the world as a totality, from a pre-critical point of view; and that he resolved the resulting antinomy by restricting the metaphysical principles of cosmology to their regulative use. For him, the topics of the 'mathematical' antinomies are indeed closely related to the theories of physics. Based on their resolution, Kant concedes Newton's absolute space only the regulative status of an ideal inertial frame, and he refutes atomism in favour of a continuum theory of matter (Kant 1786). His cosmological antinomy assumes a physical theory of the universe, which is based on Euclidean geometry and classical mechanics.

Therefore, Wind asks whether this theory has internal consistency problems that confirmed Kant in his diagnosis of an inevitable antinomy. Referring to Einstein (1917, § 30) and Seeliger (1895), he argues that in a classical, non-relativistic cosmology a physical antinomy arises which concerns the matter distribution in a Newtonian universe, and for which Kant offers a philosophical resolution by considering absolute space only as a regulative idea (Wind 2001, 67-77). He sees this physical antinomy resolved by Einstein's general relativity. Kant's second antinomy, which deals with the ultimate substances in the world, is for Wind an inverse physical and philosophical problem. He resolves it in parallel to the first antinomy, referring to Planck and Heisenberg. After so many years of debate about the interpretations of quantum mechanics we know, however, that the parallels between physics on a large and small scale are not as far-reaching as Wind thought.

\section{Finitism and the "Principle of Internal Delimitation"}

Wind has been criticized for a "conflation of the cosmological and the metaphysical” (Rampley 2001, xxi). In terms of the debate from Mach (1883) and Planck

(Rampley 2001, xxi) The latter claim holds for the 'dynamic' antinomies of freedom and necessity, but for the 'mathematical' antinomies it is much more difficult to see how it should make sense to assume that the cosmological hypotheses about the extension and the ultimate parts of the phenomenal universe could be neatly separated from an underlying ontology of noumenal substances standing in part-whole relations. 
(1908) on a unified physical world view to the recent philosophical discussion (Psillos 1999), such conflation is typical of scientific realism. So, what kind of scientific realism does Wind's account of metaphysics represent? The fact that he insists on a new understanding of metaphysics, equally opposed to empiricism as to Kant, seems to indicate a strong version of metaphysical realism. Discrepancies between the theory underlying an experiment and the measurement outcomes best represent something like hard facts for Wind, and he sees physics approximating truth by making the discrepancies disappear.

However, in this way nature manifests itself selectively, in isolated "metaphysical signals". Our epistemic access to it remains fragmentary. It can never be completed: this is the notorious problem of induction. Therefore, Wind's assumption of this metaphysical instance can hardly have more than a regulative function, like a Kantian idea of reason. Wind does not concede this, however, and so his views about the relation between metaphysics and the empirical remain unclear. To a certain extent, his scientific realism comes close to the views of Peirce (see Burch 2018) or Putnam (1981), and his scientific realism remains ambiguous between metaphysical realism and Putnam's internal realism.

Wind argues that Kant's cosmological antinomies result from "the method of external delimitation" $(2001,85)$, i.e., from asking for the boundaries of the universe and the ultimate substances or causes in the world from an extra-mundane point of view, which is (in Putnam's terms) a God's Eye View. He proposes to resolve the antinomies by determining the boundaries of the universe and the ultimate substances or causes from within, in accordance with the "principle of internal delimitation”, which indicates an internal realism in Putnam's sense:

In the physical area this means the application of an experimental process which investigates the structure of the whole on the basis of the behaviour of the parts. In philosophical terms, however, the principle is only the formal expression of the basic fact that we ourselves, together with our instruments, belong as parts to that world which is to be cognized and can therefore only investigate it 'from the inside' - on the basis of criteria supplied to us by the world itself. The 'extraterrestrial point of view' Is an absurdity. (Ibid., 86)

The "principle of internal delimitation" claims that the structure of an allencompassing physical system is already determined by the structure of the parts and can therefore be investigated by experiments in the finite. According to the principle, the parts posit a measure to the whole. This measure can be embodied in the measurements of physics and it supports inferences from the parts to the whole. Therefore, measuring instruments that embody the cosmological claims of 
twentieth century physics make it possible to replace Kant's philosophical resolution of the antinomy by "experimental reduction" (see ibid., 59). ${ }^{14}$

Wind argues that relativity and quantum theory offer new conceptions of finiteness that allow to escape the classical oppositions of a finite and an infinite world. With non-Euclidean geometry, general relativity opens the option to think of the world as a closed universe that is both finite and boundless (ibid., 78-81). With Planck's quantum of action $\hbar$ and Heisenberg's uncertainty relation, quantum theory provides a minimum size (ibid., 88-92), and he interprets the quantum indeterminacy as providing a measure for the certainty of measurement results (ibid., 107-110). Finally, he takes the contingency of spontaneous quantum processes as a case against Kant's antinomy of freedom. Recall that Experiment and Metaphysics is ultimately concerned with clarifying the concept of freedom. Wind connects quantum indeterminism with human freedom (2001, 121-125), and this was Cassirer's main point against him. ${ }^{15}$

\section{Conclusion}

Wind's claims about the relation between the empirical and the metaphysical are an interesting and original philosophical position in the philosophy of science of his day, which emerged from his neo-Kantian background and his reception of American pragmatism. His theory of the experiment opposes Carnap's empiricism, on the one hand, and the neo-Kantian constructivism of the Marburg school, on the other. In its attempt to reconcile the theory-dependence of experiments with the contingency of measurement outcomes it is closer to scientific practice than any one-sided position. However, it is far from being well-elaborated, and the accounts of metaphysics and scientific realism grounded on it are not coherent. Concerning the relation between Kant's cosmological antinomy and twentieth century physics, Wind did some pioneer work, and he was aware of it, but this was just a beginning. What remains is an ingenious proposal to connect these philosophical themes through his conception of symbolic representation via embodiment. This conception would have deserved further elaboration within the philosophy of science. Wind did not follow this path; for him, it established a bridge to his work in art history.

14 "durch Reduktion auf das Experiment” (§ 12), translated as: "by relation to the experiment" (Wind 2001, 59). Wind's expression "experimental reduction” ("Reduktion auf das Experiment") takes up Kant's comparison of the experiment of pure reason with the "experiment of reduction" in chemistry (Kant 1781/1787, B xxi). Kant's comparison is to be understood in the context of the traditional analytic-synthetic method; see Falkenburg (2018a, 2018b, 2020a, 219-221).

15 Moreover, Wind's account of freedom is related to a naturalistic account of ethics $(2001,124)$, with which Cassirer presumably even less agreed. 


\section{References}

Burch, R. 2018. “Charles Sanders Peirce." In The Stanford Encyclopedia of Philosophy (Winter 2018 Edition), edited by E. N. Zalta. https://plato.stanford.edu/archives/win2018/entries/ peirce/.

Buschendorf, B. 1985. “'War ein sehr tüchtiges gegenseitiges Fördern'. Edgar Wind und Aby Warburg." In Idea. Jahrbuch der Hamburger Kunsthalle IV, 165-209.

Buschendorf, B. 2001. Edgar Wind: Das Experiment und die Metaphysik. Frankfurt am Main: Suhrkamp.

Carnap, R. 1922. Der Raum: Ein Beitrag zur Wissenschaftslehre. Kant-Studien Ergänzungshefte, Nr. 56, Berlin: Reuther \& Reichard. Transl. in: Rudolf Carnap: Early Writings. The Collected Works of Rudolf Carnap, 1. A. W. Carus, M. Friedman, W. Kienzler, A. Richardson, and S. Schlotter (eds.). New York: Oxford University Press 2019, 21-208.

Carnap, R. 1931. “Überwindung der Metaphysik durch logische Analyse der Sprache.” Erkenntnis 2: $219-24$.

Carnap, R. 1956. "The Methodological Character of Theoretical Concepts." In The Foundations of Science and the Concepts of Psychology and Psychoanalysis, edited by F. Herbert and M. Scriven, 38-76. Minneapolis: University of Minnesota Press.

Carnap, R. 1966. Philosophical Foundations of Physics. New York: Basic Books.

Cassirer, E. 1910. Substanzbegriff und Funktionsbegriff: Untersuchungen über die Grundfragen der Erkenntniskritik. Berlin: Bruno Cassirer. Transl.: Substance and Function. Chicago: Open Court 1923. Quoted after the English edition.

Cassirer, E. 1921. Zur Einsteinschen Relativitätstheorie. Erkenntnistheoretische Betrachtungen. Berlin: Bruno Cassirer. Transl.: Einstein's Theory of Relativity. Chicago: Open Court, 1923.

Cassirer, E. 1936. Determinismus und Indeterminismus in der modernen Physik. Göteborg: Göteborgs Högskolas Årsskrift 42. Transl.: Determinism and Indeterminism in Modern Physics. New Haven: Yale University Press, 1956. Quoted after the English edition.

Cohen, H. 1871, ${ }^{2} 1885$. Kant's Theorie der Erfahrung. Berlin: Dümmler. Repr. of the 3rd ed. (1918) in: Werke, Vol. 1.1. Hildesheim: Olms 1987. Quoted after the 2nd ed. (1885).

Cohen, H. 1914. “Das Verhältnis der Logik zur Physik.” In Einleitung mit kritischem Nachtrag zur 9. Auflage der Geschichte des Materialismus von Friedrich Albert Lange, 58-94, 3rd ed. Leipzig: Brandstetter. Reprint in: Werke, Vol. 5.II. Hildesheim: Olms 1977. Quoted after: The Relation of Logic to Physics from the Introduction, with Critical Remarks, to the Ninth Edition of Lange's “History of Materialism”. Transl. by Lydia Patton, in Luft, Sebastian (ed.): The NeoKantian Reader. London and New York: Routledge, 117-136.

Crull, E., and G. Bacciagaluppi, eds. 2016.Grete Hermann - Between Physics and Philosophy. Dordrecht: Springer Nature.

Duhem, P. 1906. La théorie physique. Son objet - sa structure. Paris: Chevalier \& Rivière. Engl. transl.: Aim and Structure of Physical Theories. Princeton: Princeton University Press 1954.

Einstein, A. 1917. Über die spezielle und die allgemeine Relativitätstheorie. Braunschweig: Vieweg. Repr. in: Collected Papers 4: The Berlin Years. Writings 1914-1917, ed. by Anne J. Knox, Martin J. Klein and Robert Schumann, Princeton: Princeton University Press 1996, 420-539. Transl: Relativity: The Special and the General Theory (A Popular Exposition), London: Methuen 1920, repr. In: The Collected Papers 4 (English Translation Supplement), 247-420. 
Falkenburg, B. 2001. 78. Die Maßsetzung im Endlichen. Introduction to: Buschendorf (2001), 11-59.

Falkenburg, B. 2007. Particle Metaphysics. A Critical Account of Subatomic Reality. Berlin: Springer.

Falkenburg, B. 2018a. "Was beweist Kants Experiment der reinen Vernunft?" In Natur und Freiheit: Akten des XII. Internationalen Kant Kongresses, edited by V. L. Waibel, M. Ruffing, and D. Wagner, 641-59. Berlin: De Gruyter, Band 1.

Falkenburg, B. 2018b. "Kant and the Scope of the Analytic Method." Studies in History and Philosophy of Science, Vol. 71, 13-23.

Falkenburg, B. 2020a. Kant's Cosmology. From the Pre-critical System to the Antinomy of Pure Reason. Cham: Springer.

Falkenburg, B. 2020b. "On Method: The Fact of Science and the Distinction between Natural Science and the Humanities." In Kant Yearbook 12: Kant and Neo-Kantianism, edited by D. H. Heidemann, 1-31. Berlin: de Gruyter.

Friedmann, M. 1992. Kant and the Exact Sciences. Cambridge/Mass: Harvard University Press. Friedmann, M. 1999. Reconsidering Logical Empiricism. Cambridge: Cambridge University Press. Galison, P. 1987. How Experiments End. Chicago: University of Chicago Press.

Goodman, N. 1955. Fact, Fiction, and Forecast. Cambridge, Mass: Harvard University Press.

Grier, M. 2001. Kant's Doctrine of Transcendental Illusion. New York: Cambridge University Press. Heisenberg, W. 1969. Der Teil und das Ganze. München: Piper (Repr. in: Gesammelte Werke C III, München 1985) Transl.: Physics and Beyond: Encounters and Conversations. New York: Harper and Row. Quoted after the English edition.

Hermann, G. 1935. “Die naturphilosophischen Grundlagen der Quantenmechanik.” In Abhandlungen der Fries'schen Schule, Neue Folge, Bd. 6, Heft 2: 69-152. Bacciagaluppi and Crull: Berlin: Neues Leben 1935. Repr. in: Herrmann (2019), 205-258. Transl.: NaturalPhilosophical Foundations of Quantum Mechanics, in: Bacciagaluppi and Crull (2016), 239-278.

Hermann, G. 1996. Les fondements philosophiques de la mécanique quantique. Introduction, présentation, postface critique par Léna Soler. Paris: Vrin.

Herrmann, K., ed. 2019. Grete Henry-Hermann: Philosophie - Mathematik - Quantenmechanik. Texte zur Naturphilosophie und Erkenntnistheorie, mathematisch-physikalische Beiträge sowie ausgewählte Korrespondenz aus den Jahren 1925 bis 1982. Wiesbaden: Springer.

Hertz, H. 1894. Die Prinzipien der Mechanik in neuem Zusammenhange dargestellt. Leipzig: Barth. Transl. by T. E. Jones and J. T. Walley: The Principles of Mechanics in a New Form. London and New York: MacMillan \& Co. 1899. Quoted after the English edition.

Hilbert, D. 1925. “Über das Unendliche.” Mathematische Annalen 95: 161-90. Transl.: On the infinite. In: P. Benacerraf \& H. Putnam (Eds.), Philosophy of Mathematics: Selected Readings. Cambridge: Cambridge University Press 1984, 183-201.

Jaspers, K. 1932. Philosophie. Band II. Existenzerhellung, 3rd ed. Berlin.

Kant, I. 1781/1787. Kritik der reinen Vernunft. Riga: Hartknoch. Transl.: Critique of Pure Reason, transl. and ed.: P. Guyer and A. Wood. Cambridge: Cambridge University Press 1998.

Kant, I. 1783. Prolegomena. Transl.: Prolegomena to any future metaphysics that will be able to come forward as science. Transl. in: H. Allison and P. Heath (eds.), Immanuel Kant: Theoretical Philosophy after 1781, 49-169. Cambridge: Cambridge University Press 2002.

Kant, I. 1786. Metaphysische Anfangsgründe der Naturwissenschaft. Transl.: Metaphysical Foundations of Natural Science. Transl. and ed. by Michael Friedman. Cambridge: Cambridge University Press 2004. 
Kant, I. 1800. G. B. Jäsche (ed.), Immanuel Kants Logik. Königsberg: Nicolovius. Transl.: The Jäsche Logic, in: J. M. Young (Ed.), Lectures on Logic (The Cambridge Edition of the Works of Immanuel Kant), 517-640. Cambridge: Cambridge University Press 1992.

Krantz, D. H., P. Suppes, R. D. Luce, and A. Tversky, eds. 1971. Foundations of Measurement. San Diego: Academic Press.

Krois, J. M. 1998. "Kunst und Wissenschaft in Edgar Winds Philosophie der Verkörperung." In Edgar Wind. Kunsthistoriker und Philosoph, edited by H. Bredekamp, B. Buschendorf, F. Hartung, and J. M. Krois. Berlin: de Gruyter, 181-205. Repr. in: John M. Krois: Bildkörper und Körperschema, ed. by H. Bredekamp and M. Lauschke, Berlin: Akademie Verlag 2011, $3-$ 23.

Kuhn, T. S. 1961. "The Function of Measurement in Modern Physical Science." Isis 52: 161-93. Repr. in: Thomas S. Kuhn: The Essential Tension, Chicago: Chicago University Press 1978, 178-224.

Kuhn, T. S. 1962. The Structure of Scientific Revolutuions, 2nd ed. Chicago: Chicago University Press 1970.

Mach, E. 1883. Die Mechanik in ihrer Entwicklung - Historisch-kritisch dargestellt. Leipzig: Brockhaus. Transl.: The Science of Mechanics: A critical and Historical Account of its Development. La Salle: Open Court 1960.

Natorp, P. 1910. Die logischen Grundlagen der exakten Wissenschaften, Quoted after the 2nd ed. Leipzig: Teubner 1921.

Peirce, C. S. 1878. "How to Make our Ideas Clear." Popular Science Monthly 12: 286-302. Repr. in: Collected Works of Charles Sanders Peirce, ed. by C. Hartstorne and P. Weiss, Harvard 1965, Vol. V. Quoted after: Nathan Houser and Christian Kloesel (eds.), The Essential Peirce: Selected Philosophical Writings, vol. I (1867-1893), Bloomington and Indianopolis: Indiana University Press 1992.

Peirce, C. S. 1923. Chance, Love, and Logic, edited. by M. R. Cohen, London: K. Paul, Trench, Trubner \& Co Ltd.

Planck, M. 1908. Die Einheit des physikalischen Weltbilds. Repr. in: Vorträge und Erinnerungen, 9th ed., 28-51. Darmstadt: Wissenschaftliche Buchgesellschaft 1965.

Poincaré, H. 1902. Science et hypothèse. Paris: Flammarion. Transl.: Science and Hypothesis, London: Scott 1905.

Poincaré, H. 1908. Science et méthode. Paris: Flammarion. Transl.: Science and Method, London: T. Nelson 1914.

Psillos, S. 1999. Scientific Realism: How Science Tracks Truth. London: Routledge.

Putnam, H. 1981. Reason, Truth and History. Cambridge: Cambridge University Press.

Rampley, M. 2001. “Introduction.” In Edgar Wind, Experiment and Metaphysics: Towards a Resolution of the Cosmological Antinomies, Vol. 2001, xiii-xxviii. Oxford: European Humanities Research Centre of the University of Oxford. Paperback ed.: London: Routledge 2018.

Reichenbach, H. 1920. Relativitätstheorie und Erkenntnis a priori. Berlin: Springer. Transl.: The Theory of Relativity and A Priori Knowledge. Berkeley and Los Angeles: University of California Press 1965.

Reichenbach, H. 1922. “Der gegenwärtige Stand der Relativitätsdiskussion.” Logos 10: 316-78. Transl. in: Selected Writings: 1909-1953 (ed. by M. Reichenbach and R. S. Cohen), Dordrecht and Boston: Reidel, vol. II.

Schmitz-Rigal, C. 2002. Die Kunst offenen Wissens. Cassirers Epistemologie und Deutung der modernen Physik. Hamburg: Meiner. 
Seeliger, H. 1895. “Über das Newton‘sche Gravitationsgesetz.” Astronomische Nachrichten 138(3273): 129-36.

Sneed, J. D. 1971. The Logical Structure of Mathematical Physics. Dordrecht: Kluwer.

Stanford, K. 2017. "Underdetermination of Scientific Theory." In The Stanford Encyclopedia of Philosophy, edited by E. N. Zalta (Winter 2017 Edition) https://plato.stanford.edu/archives/ win2017/entries/scientific-underdetermination/.

Suppes, P. 1962. “Models of Data." In Logic, Methodology and Philosophy of Science: Proceedings of the 1960 International Congress, edited by E. Nagel, P. Suppes, and A. Tarski, 252-61. Stanford: Stanford University Press. Reprinted in: Patrick Suppes, Studies in the Methodology and Foundations of Science: Selected Papers from 1951 to 1969, Dordrecht: Reidel 1969, 24-35.

Tetens, H. 1987. Experimentelle Erfahrung. Hamburg: Meiner.

van Fraassen, B. C. 1980. The Scientific Image. Oxford: Clarendon Press.

van Fraassen, B. C. 1987. "The Semantic Approach to Scientific Theories." In The Process of Science, edited by N. J. Nersessian, 105-24. Dordrecht: Nijhoff.

Willaschek, M. 2018. Kant on the Sources of Metaphysics. The Dialectic of Pure Reason. Cambridge: Cambridge University Press.

Wind, E. 1934/2001. Das Experiment und die Metaphysik. Tübingen: Mohr 1934. Transl.: Experiment and Metaphysics: Towards a Resolution of the Cosmological Antinomies. With an introduction by Matthew Rampley. Oxford: European Humanities Research Centre of the University of Oxford 2001. Paperback ed.: London: Routledge 2018.

Wind, E. 1936. "Some Points of Contact between History and Natural Science." In Philosophical and History. Essays presented to Ernst Cassirer, edited by R. Klibansky, and H. J. Paton, 255-64. Oxford: Clarendon Press. Transl. from the German original: Über einige Berührungspunkte zwischen Naturwissenschaft und Geschichte, in: H. Markl et al. (eds.), Wissenschaft - Zum Verständnis eines Begriffs, Köln: Müller 1988, 34-9. 